coming various professional violations, as well as knowledge of patient's rights form the basis of the legal culture of health workers, thus are the rules of professional ethics. Streamlining the legal knowledge of the medical staff will to promote the health of the population.

Literature

1. Deryagin G. B., Kitsch, D. I. Medical law. M.: YUNITI-DANA: Law and right, 2012, -, 239 p

2. Sergeev Y. D., Grigoriev, I. Yu., Legal foundations of medical practice. Medical law. - M.: GEOTAR-Media, 2006, - 248 p.

3. Kanunnikova L. V. Ethical and legal basis of professional activity of doctor // [Electronic resource] http://base.garant. ru/55098304/.

Matyushchenko Victoria Sergeevna - Cand. of philosophical Sciences, associate Professor of Humanities Department of sbee HPE "Amur state medical Academy" Russian Ministry of health. 675000, Blagoveshchensk, Gorkogo str., 95., tel: 89638010986; e-mail: v89246728625@yandex.ru

UDC 005 DOI 10.22448/AMJ.2017.4.11-12

\title{
MANAGEMENT IN THE HEALTH OF THE AMUR REGION
}

\section{D.B. Pekov}

Management in the healthcare of the Amur region is currently of great importance in connection with the commercialization of the industry, the decentralization of state power at the level of the territories. The priority direction of health management is to reduce society's losses from morbidity, disability and mortality. To implement this direction, effective activity is required for the whole healthcare system and for each individual medical organization, for which it is required to introduce new principles and approaches, methods and models of management of all links of medical organizations aimed at:

- increasing the availability of quality and timely medical care;

- improving the quality of life of the population;

- increase the profitability of the medical organization.

The whole set of factors influencing the management of health care organizations can be divided into two groups according to the mode of occurrence:

factors of the external environment, which include:

- on the part of the state: high licensing requirements; obsolete standards for equipping medical institutions; dumping prices for paid services, established by public medical institutions;

- from suppliers: high cost of medical equipment;

- on the part of consumers: distrust of medicine.

factors of the internal environment:

- Low qualification of management personnel of medical institutions;

- lack of qualified personnel;

- shortage of financial resources.

The influence of these factors occurs in aggregate on the medical organization and lead to inhibition of the development of modern medicine. More details on the factors of the internal environment.

In modern conditions, the management of medical organizations assumes the reorientation of the functions of the chief physician into managerial ones, the head of the medical organization becomes not just a doctor, but must own the entire arsenal of management tools. Lack of economic and managerial training of a number of heads of the medical organization causes their low competence in making managerial decisions, which in turn leads to a decrease in the effectiveness of health management.

One of the most acute problems is the shortage of medical personnel, both doctors and nurses. The most effective solution to the problem of a staff shortage in a medical organization may be the creation of conditions that motivate the personnel in it to work. These conditions include:

- Relationships: in the team (general moral climate, long-term joint work and friendship, etc.); with professionals of their own or related specialties working in other collectives; with patients;

- personal benefit, i.e. all that meets the personal needs of the employee: income, status and reputation, personal connections, etc.

All described factors do not occur separately and always exist in the relationship: personal benefit and result, result and relationship, relationship and personal benefit. There is an opinion that the most important factors for most doctors 
are performance and personal gain. The administration of the medical organization needs to develop and implement a system of motivation that allows to evaluate the results of work achieved by employees and adequately reward them, encouraging the professional development of employees, with an acceptable level of expenditure for these purposes.

In addition to personnel management, competent management of the financial and material resources of the medical organization is necessary. And in the conditions of a shortage of financial resources, the economic component of medical care is becoming increasingly significant. The administration of the medical organization seeks to minimize costs, increase revenue from paid medical services, find additional sources of financing, and identify financial reserves. Most often, this is achieved through comprehensive statistical and financial control of the expenses and incomes of medical organizations, optimization of the medical process.

Analysis of the health problems of the Amur Region can be continued for a long time. However, eliminating the above factors of the internal environment of the medical organization will help to achieve a significant increase in the effectiveness of its activities.

\section{UDC 101 DOI 10.22448/AMJ.2017.4.12-13}

\section{Skobelkina Tn.}

\section{TO THE QUESTION OF THE ROLE OF PHILOSOPHY IN SHAPING THE PERSONALITY OF FUTURE DOCTORS}

\section{Of the Amur state medical Academy of Minzdrav of Russia, Blagoveshchensk}

Summary: the article gives characteristics of the main regularities of personality development, reveals the importance of philosophy for the formation of critical thinking and ethical culture of future doctors.

Key words: personality of a physician, clinical reasoning, critical thinking, humanism.

The personality of the doctor is a complex contradictory process determined by a number of objective laws. The main laws of formation of the personality N. D. Herds include: the law defining the impact of social environment on the personality, the law of the relationship of lifestyle from the interests and needs of society and the individual; the law of inverse effects of the individual to his social environment, the law of communication and isolation of the individual in society. These laws should add the growing role of the subjective factor - education and self-development emerging personality, especially in the Humanities [4].

The basic attitude of man, his value system acquire resistance 30 and further personal qualities are difficult to transform.

The development of medical science places special demands on the philosophical culture of the physician. The main objectives in the development of modern medic is the development of his professional ambitions and ability to make professional decisions. For this type of activity requires special philosophical education, including professional communication skills with a logical unit of science, the possession of deep knowledge of the methodology of science and the essential medical and biological knowledge, and skills [5].

Obviously, a doctor needs to master the craft the art of medicine, but the doctor is not enough, it needs to think philosophically. The fact is that to ensure the correct thinking without application of the basic principles of dialectics is the objectivity and comprehensiveness of the study, the study of phenomena and processes in the development, disclosure of contradictions in the very essence of the subject, unity of quantitative and qualitative analysis becomes practically impossible [1]. Philosophical and medical knowledge sinteziruemy together contribute to the formation of clinical thinking.

Philosophy and aims in addition to constant creative critical analysis of its activities. At its core, the philosophy is designed to gather knowledge from different Sciences together and to critically evaluate them. Most of the questions of philosophy to be a problematic character: the problem of existence, the human problem, the problem of matter, the problem of consciousness, etc. thus the mere speculation that is not based on critical thinking, not cast and not of crucial problematic issues, it is impossible [3].

The main method of the formation and development of personal qualities of future doctors is critical analysis and self-analysis - systematic method of learning and self-assertion of their personality through overcoming contradictions in the activity, learning and self-education.

Contemporary philosophy of medicine guided by the criterion of the spiritual value of human life, focused on Truth, Goodness, Beauty. The role of this philosophy is that it defines the limit of the base of the medicine, its common ideas, which are pivotal not only in the field of medico-philosophical perspective, but also in life in General. It is the axiological basis of therapeutic procedures, the basis of faith of the patient in their recovery, i.e. it is the spiritual element of therapeutic effects.

Since the days of Hippocrates it was believed that one who is not a good man cannot be a good doctor. Moral purity the doctor has always put on a par with the level of medical erudition and intelligence of the Clinician. Humanistic orientation of the personality of the doctor helps him overcome fatigue, constantly improve their professional knowledge, to hone diagnostic techniques, to develop creative clinical thinking. For physician-humanist his medical memory, observation, logical thinking take on special personal meaning, become its inte12 Амурский медицинский журнал №4 (20) 2017 